\title{
Bilingually traversing the US/Mexico "wall" via a classroom telecollaborative exchange: Translanguaging online with the Functional Approach to Code-switching Electronically (FACE)
}

\author{
Steve Daniel Przymus \\ Texas Christian University
}

\begin{abstract}
This study proposes to make the concept of translanguaging online accessible for teachers who wish to connect their classrooms with students in other countries via telecollaboration projects. I explore the role of instructed codeswitching, as a strategic and intentional translanguaging strategy, for developing learners' symbolic competence and in promoting the kind of communication in transnational telecollaboration projects that leads to positive bilingual identity and language development. The majority of telecollaboration projects reported in the literature describe projects at the university language classroom setting and the varied dysfunctions that may lead to "failed communication" (O'Dowd \& Ritter, 2013) or "missed communication" (Ware, 2005). In contrast, the study within describes the successful impact of a pedagogical intervention, the Functional Approach to Code-switching Electronically (FACE) (Author, 2014), that fostered intercultural understanding among public high school students in an American Government class in the Southwestern United States and students in an English as a Foreign Language (EFL) class in the Central Pacific Coast of Mexico. Findings demonstrate how teachers can adopt translanguaging practices in their classrooms by instructing the purposeful use of code-switching for facilitating the development of students' L2, content acquisition, symbolic competence, and positive identities as bilinguals. In doing so, students are given the strategies needed to successfully play within the power games situated across semianonymous online borders, walls, and contact zones (Vinall, 2010).
\end{abstract}

Keywords: Code-switching; Computer Assisted Language Learning (CALL); face; Functional Approach to Code-switching Electronically (FACE); Phatic Communication; Referential Communication; Symbolic Competence; Translanguaging

"It [CS] positioned me as an L2 user because I have never written both languages in an email before and it felt cool to write it like that."

(Pamela, student at SCRI²BE) 


\section{Introduction}

On a recent Sunday afternoon, I took a drive around the mid-size city in the American Southwest where I live and counted the billboards that advertise enrollment in local charter schools and public school districts. The billboards trumpeted their respective schools as "tech savvy", "digitally connected", "leaders in 21st Century skills and communication", and "globally connected." As a former English as a Second Language (ESL) and Spanish as a World Language high school teacher in an American school on the cusp of transitioning to a one-to-one environment, I can relate that the pressure for teachers to design and implement computer assisted language learning (CALL) pedagogy is great. The opportunity to connect classrooms with schools in other countries, seemingly at the fingertips of teachers, is a tempting panacea for meeting these tech savvy, digitally connected claims and for preparing students for competitive futures in a globally connected world. Yet, the history of telecollaboration projects, or the "use of Internet communication tools such as email and chat in order to support prolonged intercultural exchanges between groups of students in various institutional settings who might otherwise not have the opportunity to interact" (Belz, 2005, p. 4) is filled with more accounts of 'failed communication' than success stories (O'Dowd \& Ritter, 2013, p. 623; see also Belz, 2002, 2005; Belz \& Müller-Hartmann, 2002, 2003; Kramsch \& Thorne, 2002; O’Dowd, 2003, 2005; Ware, 2005; Ware \& Kramsch, 2005).

In this article, I propose a strategic pedagogical intervention that promotes translanguaging, or "the deployment of a speaker's full linguistic repertoire without regard for watchful adherence to the socially and politically defined boundaries of named (and usually national and state) languages" (Otheguy, García, \& Reid, 2015, p. 281), online in these connected learning communities. I argue that translanguaging is the missing component of failed telecollaboration projects, and its use can place needed emphasis on virtual face-work (Brown \& Levinson, 1987; Goffman, 1955; Park, 2008). In turn, translanguaging can minimize the negative cultural clashes that can come from students not sharing languages, positioning others as less proficient second language (L2) users, and not taking the time to build relationships through phatic communication. I show how increased understanding of how individuals negotiate language use and identity in the symbolic system of mobile, online communication, can prepare both teachers and students for the kinds of co-constructed knowledge and identities that form across increasingly ubiquitous online borders of semi-anonymous communicative contact zones (Vinall, 2010).

Importantly, I demonstrate how the use of a specific pedagogical intervention, the Functional Approach to Code-switching Electronically (FACE) (Przymus, 2014), facilitated the co-construction of students' content (American Government/English/ Spanish) knowledge and identities as emergent bilinguals (newcomer English Language Learners), recursive dynamic bilinguals (Spanish Heritage Learners), and dynamic bilinguals (Spanish/English as a Foreign Language Learners) (García \& Sylvan, 2011). These sociocultural aspects of co-constructing knowledge and students' identities may 
more easily be taken into consideration by teachers when students interact face-toface, but I argue, may be overlooked when the communication is online. I suggest that teachers should address the unique kind of sociocultural learning that can happen in these semi-anonymous online connected communities and nurture the development of the symbolic competence (Kramsch, 2006), or the communication power game, that students need to successfully communicate in a high school bilingual telecollaboration project.

In detailing the use and results of the FACE framework below in a U.S./Mexico high school telecollaboration project, I am acutely aware that recent literature distinguishes between translanguaging and code-switching (CS) (see Otheguy, et al., 2015) and although I, too, conceptually view them as distinct, I propose that there needs to continue to be space in the translanguaging literature for CS as a strategic and intentional pedagogical strategy for promoting discursive alignment, nurturing student identities as bilinguals, and for making the concept of translanguaging concrete for teachers. Without providing concrete examples and methods for the purposeful and strategic use of translanguaging, I fear that many teachers will continue to not positively acknowledge and encourage these kinds of fluid language practices among their students. I show how the FACE intervention (described below) promoted fluid language practices and the equal sharing of both Spanish and English in the project and placed an emphasis on relationship building through phatic communication in student online exchanges. I investigate the ways that purposeful CS, using the FACE framework, helped to mediate the development of symbolic competence, shape the identities, intercultural experiences and understanding, and L2 development of high school students in the American Southwest and the Central Pacific coast of Mexico.

In viewing the field of information exchange in online connected learning communities as a symbolic system, we can look to the mode of interaction and ask whether L2 learners possess the symbolic competence needed to mediate this symbolic system and create positive tenor and interpersonal relationships that support their desired identity development. Findings suggest that the FACE framework can provide educators with a pedagogical intervention for structuring telecollaboration projects in a way that recognizes potential challenges that accompany sociocultural interactions involving knowledge construction, identity formation, and power sharing, and thus avoid negative cultural clashes that cause telecollaboration to end in "failed communication" (O'Dowd \& Ritter, 2013, p. 623).

\section{A Functional Approach to Code-switching Electronically (FACE)}

I posit that many of the problems reported in past telecollaboration projects have to do with the concept of face, or "the positive social value a person effectively claims for himself" (Goffman, 1955, p. 213), brought on largely by clashes of discourse styles, such as a lack of establishing norms and a lack of alignment among participants. Based 
on a 2003 Spanish-English telecollaboration project, O'Dowd "found that the essential difference between the successful and unsuccessful partnerships was whether students had the intercultural competence to develop an interculturally rich relationship with their partners through the creation of effective correspondence" (O'Dowd \& Ritter, 2013, p. 626).

In this study I explore whether it is intercultural competence alone that students need or also the symbolic competence to manipulate the discourse in order to create the discursive alignment needed among interactants for the communication to continue. I call for here a purposeful use of CS as a pedagogic strategy for promoting this discursive alignment. Some researchers, such as Arthur \& Martin (2006), have recognized the "pedagogic validity" of CS and consider CS a "teachable" educational resource (p. 197; see also Przymus, 2016, 2014; Creese \& Blackledge, 2010; Garcia \& Sylvan, 2011). Creese \& Blackledge (2010) propose that student bilingual practices in the classroom may be both seen as "a way to save face with regard to different levels and proficiencies in the two languages", and also as "a style resource (Androutsopoulos, 2007) for identity performance to peers" (p. 110). CS as a pedagogical style resource/learner strategy for identity and content development can be understood as students enacting symbolic competence in order to position oneself as a multilingual subject (Kramsch \& Whiteside, 2008), to "perform and create alternative realities" (Kramsch \& Whiteside, 2008, p. 666), to create and find appropriate subject position between languages (Kramsch, 2009), and to manipulate semiotic practices to make and convey meaning (Kramsch, 2006).

Translanguaging describes the language practice and ability of multilinguals to utilize their full linguistic repertoire, that includes features of multiple named languages, but are all part of an individual's sole linguistic system (idiolect) (Przymus, in press; see also Otheguy et al., 2015). Pedagogically encouraging translanguaging through the strategic use of CS in this study actually may have empowered students to use more of their full linguistic repertoire, than had the project been structured for just L2 use, allowing them to claim the social value or face as a bilingual individual. Below, I analyze what face-work and identity performance looks like online in a transnational high school telecollaborative exchange and ask in the absence of all physical semiotic resources, such as gestures and facial expressions, how can CS be purposefully instructed and strategically used to enhance students' positive social value or face in an online intercultural interaction? Tsiplakou (2010) defines the online purpose of CS as "linguistic signaling of symmetrical social alignment" (p. 381). This social alignment is an example of demonstrating the symbolic competence needed to manipulate the linguistic practice of the context, establish one's multilingual online identity, acknowledge the bilingual ability of one's online partner, and work toward the symmetry needed for a successful online communicative interaction and telecollaboration project. I propose that instructed CS could be seen as a dialogic pattern utilized for establishing norms that protect and preserve new bilingual identities.

The pedagogical intervention used in the current study was the Functional Approach to Code-switching Electronically (FACE) (Przymus, 2014), a multi-theoretical approach that combines translanguaging (Otheguy, et al., 2015), Jakobson's (1990) speech functions 
(see Figure 1 for an example, Przymus, 2014), and systemic functional linguistics (SFL) (Eggins, 2004; Halliday, 1978; Martin, 2000). Drawing connections in the literature, Warschauer \& Grimes (2007) provide a precursor of this kind of social semiotic analysis of CS. Warschauer \& Grimes (2007) refer to CS (which I see as the mode in SFL, or how someone chooses to organize the text) as a strategy for "exercising authorship" on Web 2.0 platforms. They consider the form of text "artifact," which I use as the field in SFL, or the actual written post or content that creates shared knowledge, and Warschauer \& Grimes consider the "audience" involved, which I use as the tenor in SFL, or the interpersonal identities created as a result of the exchanges, which is often multilingual, global, and almost always unseen/imagined in order to ultimately exercise authorship and create an online identity.

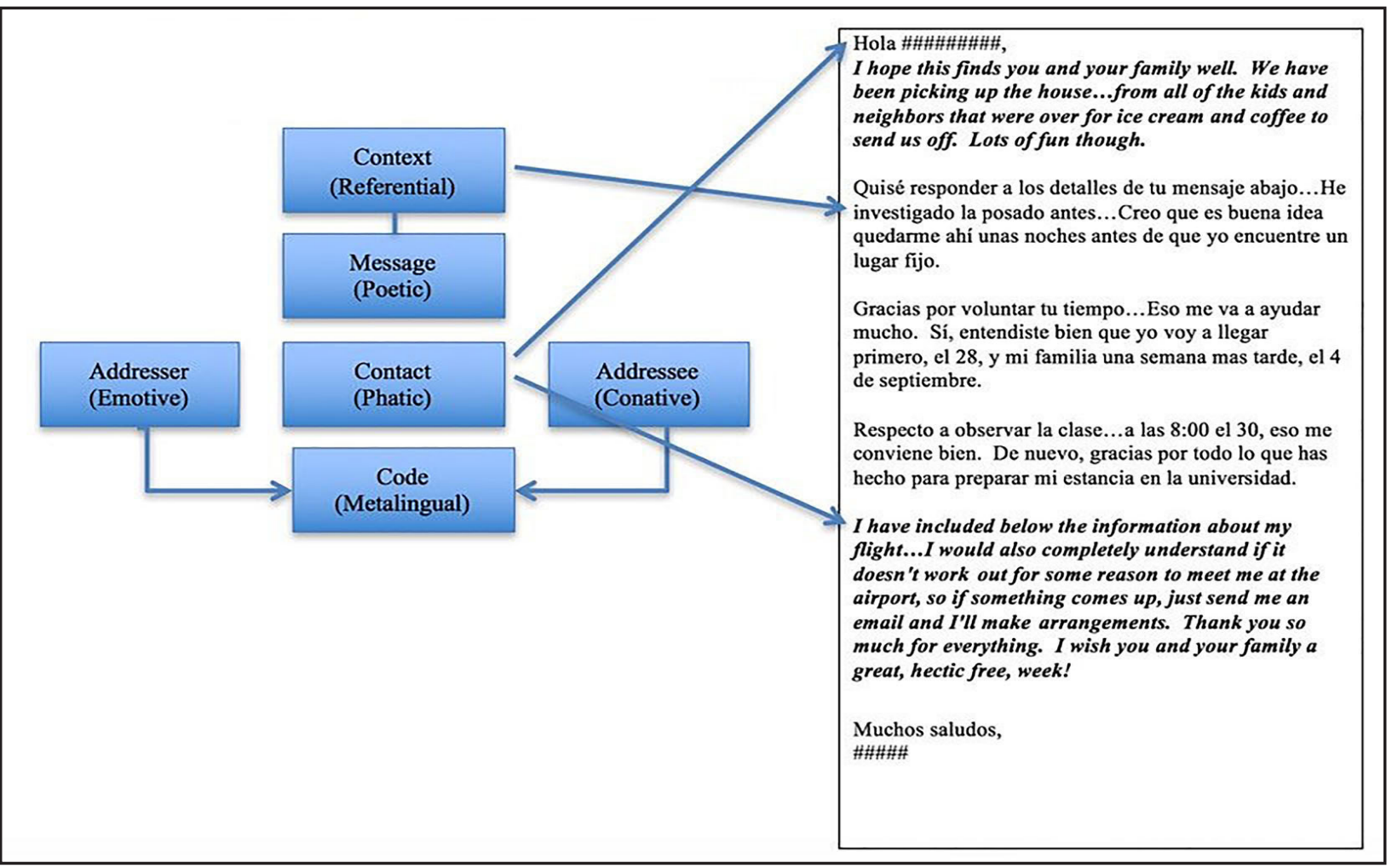

Figure 1. Using Jakobson's (1990) speech events and functions to show the phatic-referential switch in an email (Przymus, 2014).

The FACE framework organizes the flow of a telecollaboration exchange into three parts, accomplished by two phatic-referential switches. Figure 2 below illustrates the FACE framework and an example of how it was used in a post for a theme on "interactions with tourists/transnational consumers" during the current study. The first phatic contact at the beginning of an interaction is an extended greeting. This extended greeting is important for the establishment of a positive tenor, or interpersonal relationship in the telecollaboration. This can be done in either the composer's L1 or L2, and will determine the language of the referential function as the opposite language. 


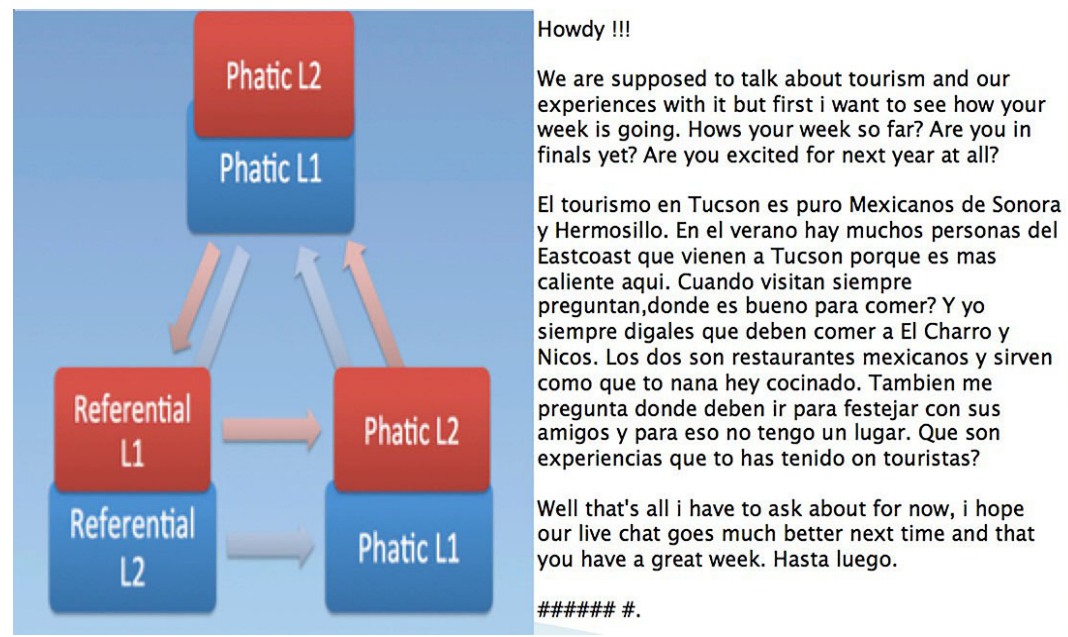

Figure 2. The FACE framework

Switching languages from the first phatic contact to the referential part of the interaction sends a natural message that the focus will now shift to a more educational discourse related to the topic or theme of the lesson to be discussed. This first phatic-referential CS also sends the message that both languages will be shared in the dialogue and that the writer assumes a bilingual competence of the interactant that acts to position neither as superior nor inferior in L2 proficiency. A CS back to phatic information to end the exchange serves two purposes. First, in considering the three metafunctions of SFL, we can see that this referential-phatic switch at the end of the email is an example of the textual flow, or mode, of the text once again fusing the ideational resources with the interpersonal resources in order to strengthen the positive tenor at the end of the interaction. Secondly, since most referential (thematic) parts of an interaction will likely be longer than the initial phatic connection, returning to the phatic function at the end works to balance the amount of each language used in the exchange, thus privileging the L2 competencies of both interactants and enhancing the positive bilingual face of both.

The FACE framework requires the alternation of the initiating language in subsequent telecollaboration exchanges. This gives each individual the opportunity to demonstrate L2 proficiency in both the phatic and referential functions of interactions over an extended correspondence. Through teaching students how and why to share languages online in this manner, they may develop the symbolic competence needed to successfully negotiate language use online, receive the scaffolding needed to meaningfully practice both languages in ways that allow them to position themselves as multilingual subjects, and push back against deficit narratives of CS as broken or confused language use. This last point is especially true for recursive dynamic bilinguals, who are often situated in U.S. schools with identities as speakers of Spanglish and street Spanish; identities laden with guilt for not speaking Spanish well enough and/or sounding White (Przymus, 2016). 
In the following section, I describe how I, from the standpoint of a researcher and theoretically informed teacher, investigated how the FACE framework facilitated purposeful CS and the impact that this pedagogical intervention had on students' intercultural, language, and symbolic competence development and on the overall success of the telecollaboration project. Participant perceptions of the project from semistructured focus group interviews, daily journal entries, and online anonymous surveys are triangulated with direct teacher-researcher observations, and an analysis of all of the telecollaboration posts to address the following research questions:

1. To what extent did the FACE pedagogical intervention promote codeswitching throughout the project?

2. In what ways did students perceive that this instructed CS aided in deepening their overall understanding of their partners' culture?

3. In what ways did students perceive that CS facilitated their L2 learning and practice?

4. To what extent did purposeful CS and the attention to phatic/referential switches in this transnational telecollaboration project mediate the development of symbolic competence and facilitate students' ability to position themselves with identities as successful L2 users?

5. To what extent did students perceive that this purposeful CS aided in creating and maintaining positive and respectful relationships with their telecollaboration partners and had an impact on the overall success of the project?

As an invited researcher and teacher in the U.S. school, it was my goal to gain first hand experience with the work and pressures that are part of everyday lesson preparation, student interaction and assessment, and project preparation and maintenance, including the very important relationship maintenance with my counterpart teacher and institution in Mexico, and while doing so, continuously cross-check these experiences with the critical voices in the literature regarding the dysfunctions of telecollaboration projects. In doing so, I confronted my own symbolic competence development as a multilingual and educator/participant of transnational telecollaboration.

\section{The Study}

\section{Profile of Participants and Setting}

In order to respect and protect the privacy of the participants, all proper namesinstitutional as well as personal-have been changed. The networked American-Mexican learning community reported on in this study consisted of a high school dual-language immersion American Government class (specially created for this research study) at the 
Southwest College Readiness Institute of Inquiry Based Education (SCRI'BE), a public charter high school in the Southwest of the United States and an advanced level English as a Foreign Language (EFL) class at the Colegio Cima de Triunfo (CCT), a wealthy, private high school in the Central Pacific coast of Mexico.

Embedded within this networked learning community were 21 American and 20 Mexican students. The $\mathrm{SCR}{ }^{2} \mathrm{BE}$ classroom, composed of one emergent bilingual from Mexico, who had been in the U.S. for less than a month at the beginning of the project, 11 recursive dynamic bilinguals (all falling on a wide continuum of social and academic Spanish proficiency), and nine English dominant dynamic bilinguals, with very little Spanish as a world language class experience and no previous experience learning content in Spanish, all partnered with the 20 advanced level EFL students at CCT, creating a rich and complex telecollaboration experience for both classrooms.

\section{Data Collection Instruments}

Student journal entries. Each day before, the day of, and the day after a telecollaboration exchange, students were given journal prompts in order to 1) anticipate the kinds of interactions they thought they would have, 2) summarize the current day's exchanges, and 3 ) interpret the previous day's interaction. These journals were collected and analyzed for recurring themes on language learning, development of symbolic competence, status of relationship with partners, and perceptions on project success.

Synchronous and asynchronous exchanges. The 149 synchronous chat posts were analyzed for occurrences of CS and for content that positioned interactants as either more or less proficient in their L2. The 141 asynchronous email exchanges were analyzed for the same linguistic and discursive features.

Anonymous online surveys. The American students completed two formative anonymous online surveys, one after the first two weeks of the project, the second after the fifth week of the project, and a final summative survey at the end of the nine-week project. Survey questions ranged from how students rated the overall success of this project, how they rated their relationship with their project partner in Mexico throughout the project, and whether or not they perceived CS having facilitated their L2 practice and positioned them with an identity as a bilingual in the project. The Mexican students completed the same anonymous online survey after the completion of the project. All survey responses were analyzed for the same recurring themes of target language and culture learning, project impact on intercultural understanding, the status of the relationships between partners, and participant perceptions regarding their own symbolic competence and the success or failure of the project.

Focus group interviews. All students at the U.S. high school participated in either the course final L1 Spanish-speaking focus group interview, consisting of recursive dynamic bilinguals and the one emergent bilingual, or in the L1 English-speaking group, made up of dynamic bilinguals learning Spanish as a world language. The semi-structured focus group interview questions varied from asking students to relate stories from the project 
when their CS positioned them with an identity as a bilingual, share stories regarding L2 and intercultural learning, and whether they thought that sharing languages and including phatic communication in each post helped facilitate and maintain a positive relationship with their partner. At the completion of the project, I traveled to Mexico and conducted the same focus group interview with all of the Mexican student participants.

Teacher-researcher journal observations and journal entries. Finally, the above data were triangulated with my own teacher-researcher daily observations and journal entries that I completed everyday immediately after each class.

\section{Pedagogical Procedure}

As the teacher of the dual-language American Government classroom at SCRI ${ }^{2} \mathrm{BE}, \mathrm{I}$ shared my previous experience with telecollaboration projects and 2014 research detailing the FACE framework with the 21 American students, prior to beginning Phase 1 of the project. During this pre-project preparation, we discussed the meaning of CS, phatic vs. referential communication, discussed possible cultural differences in the amount of phatic communication, how to switch languages at the phatic/referential changes of a post, what this might mean for positioning oneself as bilingual, discussed strategies for writing in the students' L2, such as copying how their Mexican partner writes phatic and referential language in Spanish, and discussed how to alternate order of language use by Google Group post, as per the FACE framework.

Phase 1. Phase 1 consisted of six weeks of asynchronous email exchanges via a Google Group called "Atravesando (Crossing) Borders" and in total accounted for 141 student exchanges $\left(S C R I^{2} B E=99 ; C C T=42\right)$. Due to a difference in time zones and class scheduling, the weekly exchanges were separated by several hours with usually the CCT class posting first. The themes, described in Table 1 below, were designed in collaboration between the two teachers with the goal of dispelling myths regarding each other's country and culture and to question both local and intercultural language/race ideologies.

Table 1.

Phase 1 asynchronous Google Group telecollaboration themes

\begin{tabular}{|l|l|}
\hline \multicolumn{1}{|c|}{ Exchange Theme } & \multicolumn{1}{c|}{ Theme Description } \\
\hline $\begin{array}{l}\text { "We are so much more } \\
\text { than..." }\end{array}$ & $\begin{array}{l}\text { Students contrasted stereotypes and the reality of } \\
\text { their country. }\end{array}$ \\
\hline $\begin{array}{l}\text { Our linguistic } \\
\text { landscape }\end{array}$ & $\begin{array}{l}\text { Students analyzed the language/race ideologies of } \\
\text { signs in their neighborhoods. }\end{array}$ \\
\hline Educational systems & $\begin{array}{l}\text { Students compared and contrasted their educational } \\
\text { systems. }\end{array}$ \\
\hline
\end{tabular}




\begin{tabular}{|l|l|}
\hline Our Constitution & $\begin{array}{l}\text { Students compared and contrasted their constitutions } \\
\text { and multimodally presented constitutional } \\
\text { amendments with poems, drawings, raps, and } \\
\text { videos. }\end{array}$ \\
\hline Spring Break check-in & Posts meant to maintain phatic communication. \\
\hline $\begin{array}{l}\text { No theme/exchanges- } \\
\text { Holy Week }\end{array}$ & $\begin{array}{l}\text { Students shared experiences interacting with tourists } \\
\text { and immigrants. }\end{array}$ \\
\hline Tourism/immigration \\
\hline
\end{tabular}

Figure 3, below, shows a post from an L1 English-speaking student in the U.S. and is typical of the kinds of critical language awareness discussions that arose from the linguistic landscape theme.

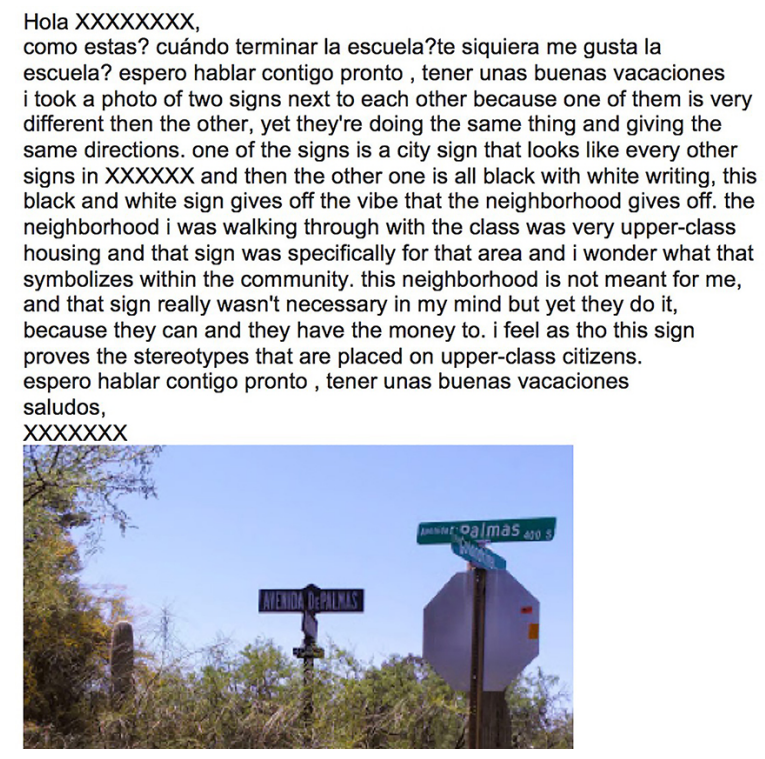

Figure 3. Analysis of Spanish language street signs in the U.S.

We can observe in this post that the student uses FACE to position himself as bilingual and is able to take on an important topic regarding wealth and stereotypes in his local context.

Phase 2. Phase 2 was made up of one synchronous chat session during the eighth week of the project. The students predetermined that the theme of the chat session would be the same as the first asynchronous exchange theme, "We are so much more than...". In total there were 149 chat exchanges during a 35 -minute session $\left(\mathrm{SCRI}{ }^{2} \mathrm{BE}=82 ; \mathrm{CCT}=\right.$ $67)$. 
Phase 3. Phase 3 consisted of one video conferencing session via Skype. Prior to the Skype session, students in each country identified five possible questions (Table 2) to be used during the videoconference.

Table 2.

Skype session questions by classroom

\begin{tabular}{|c|c|}
\hline \multicolumn{1}{|c|}{ SCRI'BE (U.S.) } & \multicolumn{1}{c|}{ CCT (Mexico) } \\
\hline 1. What do you like to do for fun? & $\begin{array}{l}\text { 1. Which career would you like to } \\
\text { pursue? }\end{array}$ \\
\hline $\begin{array}{l}\text { 2. What is your school really like? Do you } \\
\text { wear uniforms, what is your schedule, } \\
\text { what does your school look like? }\end{array}$ & $\begin{array}{l}\text { 2. Now that this intercultural- } \\
\text { interaction project is coming } \\
\text { to an end, how has your } \\
\text { perspective changed? }\end{array}$ \\
\hline $\begin{array}{l}\text { 3. What do you think about immigration? } \\
\text { Immigration into Mexico from Central } \\
\begin{array}{l}\text { America, immigration from Mexico into } \\
\text { the U.S.? }\end{array}\end{array}$ & $\begin{array}{l}\text { 3. What do you think about } \\
\text { the misconception that all } \\
\text { Mexicans are lazy and wear a } \\
\text { big sombrero? }\end{array}$ \\
\hline $\begin{array}{l}\text { 4. Do you know anyone personally who } \\
\text { has emigrated to the US? }\end{array}$ & $\begin{array}{l}\text { 4. What is your opinion about } \\
\text { people who discriminate } \\
\text { Latinos? }\end{array}$ \\
\hline $\begin{array}{l}\text { 5. Do you know anyone who has grown } \\
\text { up in the US, but was deported to } \\
\text { Mexico and now attends school in } \\
\text { Mexico? }\end{array}$ & $\begin{array}{l}\text { 5. What is the reason why you call } \\
\text { yourselves Americans? }\end{array}$ \\
\hline
\end{tabular}

As is notable in the table above, students' questions contained a combination of phatic content regarding hobbies and future goals and much more critical referential/themebased questions regarding racism and immigration. The critical nature of these questions speaks to the comfort level that the students had with their partners at this final stage in the project. Students' comments below point to how CS gave the students a sense of being on an equal footing with their partners. The two teachers decided not to place rigid guidelines for language use during the Skype session, but encouraged the students to take turns speaking Spanish and English. This was accomplished by rotating through project partners who sat in front of the main computer that was connected to a projector. Each partner asked one question and the classes as a whole provided bilingual support to their spokesperson in answering the question.

Below I relate the findings of the study, by phase and mode of interaction. I begin by addressing the first research question, regarding to what extent the FACE intervention promoted CS throughout the project, by quantitatively reporting the number of CS from an analysis of all the project's asynchronous and synchronous exchanges. Qualitatively, I draw on responses from the anonymous online surveys, semi-structured focus-group interviews, journal entries, an analysis of all of the archived Google Group 
asynchronous email exchanges and synchronous chat posts, and my own teacherresearcher observations to report on participant and my own perceptions regarding the role of purposeful CS on the research questions focusing on target language and culture learning, the development of symbolic competence and identity formation as proficient bilinguals, and the development and maintenance of relationships and project success.

\section{Findings}

\section{Code-switching in the Asynchronous and Synchronous Exchanges}

To address the first research question regarding to what extent did the FACE pedagogical intervention promote CS throughout the project, all 290 student exchanges were analyzed. Tables 3 and 4 below show the total number of CS by classroom and the language of the non-CS asynchronous and synchronous exchanges.

The American students CS more than the Mexican students during Phase 1 with a total of $72 \%(71 / 99)$ of their exchanges containing some CS, compared to $67 \%(28 / 42)$ of the Mexican students' emails containing some CS. This discrepancy of CS by classroom could in part be explained by the fact that the American students received explicit training, prior to beginning the project, on the FACE framework. The fact that the Mexican students did not receive this training, but still CS in $67 \%$ of their exchanges, offers evidence of symmetrical discursive alignment needed for telecollaboration success.

When the American students did not CS, they favored Spanish as the sole language of the email in direct contrast to the Mexican students who almost completely favored English as the language of non-CS emails. Perhaps one of the most fascinating findings of these non-CS emails was that $100 \%$ of the non-CS emails written by the Mexican students (13) were direct responses to all Spanish language written emails, published first by their American counterparts. Both the Mexican and American students were more likely to CS in response to an email containing CS from their partner and were more likely to respond to an email written solely in their L1 with their own email constructed solely in their L2.

Table 3.

Code-switching by country in asynchronous discussion board exchanges

\begin{tabular}{|l|l|l|l|l|}
\hline & $\begin{array}{c}\text { Posts with } \\
\text { CS }\end{array}$ & $\begin{array}{c}\text { All English } \\
\text { Posts }\end{array}$ & $\begin{array}{c}\text { All Spanish } \\
\text { Posts }\end{array}$ & $\begin{array}{c}\text { Total \# of } \\
\text { Posts }\end{array}$ \\
\hline SCRI'BE (U.S.) & 71 & 11 & 17 & 99 \\
\hline CCT (Mexico) & 28 & 13 & 1 & 42 \\
\hline
\end{tabular}


Table 4.

Code-switching by country in synchronous live chat exchanges

\begin{tabular}{|l|l|l|l|l|}
\hline & $\begin{array}{c}\text { Posts with } \\
\text { CS }\end{array}$ & \multicolumn{1}{|c|}{$\begin{array}{c}\text { All English } \\
\text { Posts }\end{array}$} & $\begin{array}{c}\text { All Spanish } \\
\text { Posts }\end{array}$ & $\begin{array}{c}\text { Total \# of } \\
\text { Posts }\end{array}$ \\
\hline SCRI'BE (U.S.) & 19 & 36 & 27 & 82 \\
\hline CCT (Mexico) & 31 & 32 & 4 & 67 \\
\hline
\end{tabular}

Table 4 shows that participants also demonstrated CS during Phase 2, the synchronous chat session, although not with the same frequency as in Phase 1. This, perhaps, is not that surprising considering that asynchronous email exchanges afford students more time to think about what they are going to write and more time to construct bilingual emails. Whereas, in synchronous chats students are more likely to get caught up in the immediacy of the conversation and content and think less about the bilingual structure of their posts. During the chat session, the Mexican students CS with greater frequency than their American partners, with 46\% (31/67) of their chats containing some CS, compared to just $23 \%$ (19/82) of the American students' chats containing some CS.

The chat session was quite difficult for the L1 English-speaking students at SCRI'BE, who were beginning Spanish language learners. Some acknowledged that it would be difficult, but that they could copy certain linguistic aspects (phrases and words) of their partners' chats and learn more that way. In an anonymous online survey response one $\mathrm{SCRI}^{2} \mathrm{BE}$ student wrote, "I feel I at least know some basic terms because I've been able to copy my partner's dialogue." The chat session brought the issue of the Mexican students being more proficient in their $\mathrm{L} 2$ to the forefront as evidenced by the following anonymous online survey response by an American student:"Yes there has been a lot of code switching, and I think this is because they are doing a lot of English learning and are really good at code-switching. I feel like my partner did a lot better than me and I regret that I don't know more spanish to be able to better share languages."

There is a sentiment of lament in this response by the American student not being able to share languages as much through using more Spanish, but also a sense that she is not as able to position herself as much as her partner as a proficient bilingual. There also is an unwritten sense that CS has sheltered this student somewhat from being completely positioned as linguistically inferior with her partner.

Chatting synchronously in Spanish was also a challenge for some of the recursive dynamic bilinguals at $\mathrm{SCR} \mathrm{I}^{2} \mathrm{BE}$. As stated above, these students possess a large variety of proficiency in spoken social and academic Spanish, but most struggle with writing and reading in Spanish. The potentiality of youth to use their symbolic competence to position themselves as a proficient L2 users by manipulating the mode of transnational semi-anonymous communication through CS comes out in a journal entry written by Joey, a freshman recursive dynamic bilingual at SCRI ${ }^{2} \mathrm{BE}$, who expressed in the focus group interview that his Spanish language abilities, prior to this class, had almost all faded away. In answering a journal prompt asking students to think about how they will 
interact in the following day's chat session, Joey writes:"My strategy for tomorrow is code-switch as frequent as often. I don't know many words in Spanish aside from what I have learned in class, so I'm going to representar any words I know en español in Spanish so that way yo can minimally get an understanding of how to code-switch on a more advanced level.»

We can see from the bolded Spanish words in Joey's journal entry that Joey was using his journal prompt to practice CS for the next day's chat session.

\section{Code-switching in the Skype Session}

According to all of the students in their separate focus group interviews, Phase 3 was by far the most popular mode of interaction. In the Mexican post-study interview, a female student, Sandra, related that Skype was the best because "You can see their reactions... you can see what the person is thinking and you can see their expressions." In the same interview, a male student, Tomás, conjectured that it depends on what you want to practice, between writing or speaking, remarking "In chat you can correct your mistakes, but on Skype you feel nervous awkward." In my own observations, I noted that this nervousness felt by the students and the awkward feeling, caused in part by frequent freezing of the screen and background noise impeding the students hearing each other, made the sharing of languages much more difficult. The Mexican students were capable of using both languages to ask and answer questions and although several L1 Englishspeaking American students attempted to use Spanish during Skype, a recursive dynamic bilingual classmate had to clarify in all cases and repair broken dialogues.

The Skype session, although popular with the students, did unmask the real language proficiencies that CS in asynchronous and synchronous written exchanges worked to shroud, and thus was a larger threat to the positive face (Brown \& Levinson, 1987) of the students from SCRI ${ }^{2} \mathrm{BE}$. I posit, however, that prominence placed on developing interpersonal relationships through consistent adherence to the FACE approach of CS at phatic-referential switches during the first two phases, may have worked to create positive relationships between partners that were strong enough to weather the awkward, faceto-face interaction via Skype. Indeed, no students mentioned in focus group interviews that they felt negatively positioned as less proficient in their L2. Pamela, a female student at SCRI ${ }^{2} \mathrm{BE}$, supported this idea by claiming in the L1 English-speaking focus group that she developed a close relationship with her partner because her partner would write a lot in both languages and that this made her feel good about trying to write some in Spanish, knowing that her partner would respond in a similar way. Pamela, who attempted a few words in Spanish during the Skype session, went on to say in the interview that "Yeah, my partner, I just saw on Skype and she had to go real quick, but I was like 'hey l'm your partner and she was like 'OH!!' and we got to know each other like what she likes, like music and food." This sentiment of finally seeing their partners' face was expressed by many participants from both classrooms during interviews and online surveys, and it seems that the ability to put a face to the relationship that they built over the previous eight weeks outweighed any negative threat of positioning each other as either more or less proficient during the face-to-face interaction. 
Having shared how the FACE pedagogical intervention encouraged and promoted a culture of CS throughout the project, I now turn to the second and third research questions and investigate how this structure of CS had an impact on students' L2 and target culture learning. Below, students' voices are shared regarding specifically how their experience using two languages in the project facilitated their learning.

\section{Target Language and Culture Learning}

Telecollaboration projects are seen as an essential 21st century practice for expanding learners' knowledge of and interaction with L1 speakers of the target language, and for exposing students to authentic language use, such as the practice of CS (Thorne \& Black, 2007). Students in both countries tended to perceive that this project energized their language learning and provided authentic language and 'real' cultural learning. Several American students self-reported on the anonymous online surveys that "I have always wanted to be a fluent Spanish speaker but I never want to put the time in. Now that it's part of a class, I feel more motivated to do so."; "I learned that the stereotypes that I placed on Mexico and their way of life are not true and I'm glad I had the chance to know that their [sic] are limits and restrictions within their country."; and "from my partner $i$ learned new things about Mexico that they never show on the news." This last quote is especially positive for the potential 'real' learning that can take place in successful telecollaboration projects, in light of the timeline of this course corresponding with the lead-up to the U.S. presidential election and all of the anti-immigrant (mostly Mexican) rhetoric that students were exposed to in the news.

The role that CS played on language and intercultural learning was not lost on the participants. A Mexican student punctuated this writing the following on an online survey, "La verdad que me agrado mucho el proyecto y siento que fue un exito por que interactuamos con distinta gente e intercambiamos conocimientos de los dos idiomas" ("Truthfully, I really liked the project and felt that it was a success due to the fact that we interacted with people different from us and exchanged knowledge in both languages"). An American student showed gratitude for the purposeful CS with the following survey response, "We have the opportunity to write in English or Spanish every time we write, and my parents speak Spanish so I can practice with them."

Reframing CS as an accepted and valued practice and dispelling the myths that CS is somehow a 'mixed-up' or 'confused' way of communicating had a positive impact on all students, but it specifically emboldened the recursive dynamic bilingual youth at SCRI ${ }^{2} \mathrm{BE}$, who reported having been made fun of for what others called their 'bad Spanglish'. Armed with a positive view of CS, students throughout the project acknowledged CS as a tool for successful communication and a bridge towards improving their L2 development. Joey, whose comment on CS is shared above, documented the following in a journal entry, "I think that it will be a new approach to a language that I have struggled with for 16 years. I think that code-switching will help me see which context to use Spanish words in." 
Several comments posted to the final anonymous online survey by the American students support CS as a tool for language learning. The following comments are representative of the overall American students' views of learning through CS:

- "I feel that code switching has positively impacted me in using both English and Spanish."

- "I feel like when it does happen it really does help my brain feel more active in the process."

- "I believe the code switching is good because I get to hear 2 languages."

- "It's easier to go between languages"

- "It has allowed me to learn the same or similar content in different languages which I feel just helps my brain activity."

- "I like code switching. It relieves the pressure of being correct in every word of Spanish that I speak."

- "Melding two languages together, when I already know one language well, is really helpful, at least."

The Mexican students also commented on how CS facilitated the success of their overall communication in the project. One student posted on the anonymous online survey that "la verdad me gustó mucho eso porque si no sabíamos como expresar una palabra en inglés o una frase lo podíamos decir en español." "The truth is, I really liked that [using two languages] because if we didn't know how to express a word in English or phrase, we could say it in Spanish"). Another Mexican student expressed a similar sentiment on the same survey, stating "Me pareció muy bien, porque teniamos que hablar en los dos idiomas seguido, lo cual ayudó a sentirnos mas confiados y seguros." ("It seemed very good, because we had to talk in both languages together, it helped us feel more confident and self-assured"). It is specifically this feeling of self-assurance and confidence that educators want to have their students experience while learning, in hopes that they will develop positive identities as dynamic bilinguals and want to continue learning and using their L2.

I now turn to the students' voices regarding their potentiality to position themselves as multilingual individuals (Kramsch \& Whiteside, 2008; Vinall, 2010) through CS, and address the fourth research question concerning to what extent did purposeful CS and the attention to phatic/referential switches in this transnational telecollaboration project mediate the development of symbolic competence and facilitate students' ability to position themselves with identities as successful L2 users.

\section{Self and Group Positioning with Bilingual Identities}


Marcos, a 17-year-old recursive dynamic bilingual at SCRI ${ }^{2} B E$, summed up well the potentiality of youth to purposefully employ bilingual competence in the symbolic system of online communication, through his recognition of the impact that CS might have for learners' identity formation. In the L1-Spanish focus group interview Marcos stated,"people see you differently if you just speak English or you just speak Spanish or you speak both. And I feel like everyone categorizes, naturally people categorize each other, so doing that [CS] it's like they see you differently, then they know that you speak Spanish and English."

For the American students who were learning content in two languages and bilingually communicating transnationally for the first time, this project at times was very difficult. Several students mentioned that they felt dumb because they could not write with the same amount of depth and intellect in Spanish as they could in English. However, I submit that the simple fact that the structure of the FACE approach (described above) encouraged these students to write in Spanish on every post, kept these students from falling into the self-imposed or partner-imposed positioning as a less proficient $L 2$ user, which past telecollaboration studies have shown leads to withdrawal, lower motivation, less L2 practice, and negative attitudes regarding the learning of another language (Belz, 2002; Müller-Hartmann, 2000a; O’Dowd \& Ritter, 2013). To lend support to this claim, Pamela, an L1 English speaking student from SCRI ${ }^{2} B E$ who frequently CS during the project, acknowledged in a journal entry that "It [CS] positioned me as an L2 user because I have never written both languages in an email before and it felt cool to write it like that."

If CS aided in students claiming positive social identities, what impact might it have had on the overall success of the project, which so often is indicated by the kinds of relationships formed between partners? Looking at the findings, I now take up the final research question and describe to what extent the students perceived that CS helped them create and maintain positive and respectful relationships with their telecollaboration partners and if this had an overall impact on the success of the project.

\section{Positive and Respectful Relationships for Project Success}

Symbolic competence in transnational telecollaboration must include understanding the symbolic practices of individuals that differ across culturally specific figured worlds. One such cultural practice is the tendency to use phatic language. If no pedagogical intervention were implemented, would the U.S. and Mexican students differ in the amount and tendency to use phatic communication in their online exchanges? Many Spanish speakers, at varying levels depending on country and region, place an importance on creating a personal relationship before getting to the 'business' of a dialogue (Fant \& Grindsted, 1995; Grindsted, 1994, 1995; Placencia, 1998, 2005). Androutsopoulos (2013) has shown that “...CMC interlocutors use code-switching, style shifting, and other manipulations of written signs in order to accomplish pragmatic work that would be accomplished by phonological variation, prosody, gaze, posture, and other cues in ordinary spoken conversation" (p. 670). The social alignment, accomplished by giving time to phatic communication through CS may have created relationships in this 
telecollaboration project based on deeper engagement in getting to know the project partners. In an anonymous online survey, a Mexican student suggested as much, by writing: "The fact that most of the students did have a mixture of languages and we also put forth the effort to do so in order to aid in their learning as well. Along with the fact that I felt everyone put in an effort to share things of interest when writing to their partner."

After just two weeks into the project, an American student responded to the online survey with the following explanation why he thought the project was at that point a success. "The depth of the posts, the use of both languages, and the high level of phatic communication used to create relationships."

Findings from all sources of data collection indicate that the participants saw this project as a success and wished for it to continue into the next school year. According to the responses to the formative and summative anonymous online surveys, after two weeks into the project, $79 \%$ of the American students evaluated the project as either "very" or "somewhat successful", with the other $21 \%$ indicating that the project was "neither successful nor unsuccessful". At the end of the project $88 \%$ of the American students rated the project as either "very or somewhat successful", with the other $12 \%$ reporting that they saw the project as 'neither successful nor unsuccessful'. The Mexican students also assessed the project in favorable terms. In a post-project anonymous online survey, $71 \%$ of the students felt the project was "very successful" and the remaining $29 \%$ reported that the project was "somewhat a success".

More specific findings regarding project success linked to language learning, learning about partners' culture, and the formation of friendships arose in the focus group interviews and in student journal entries. In the post-project class interview in Mexico, Mateo, a male student at CCT described the success of the project in terms of intercultural understanding and referring to the telecollaboration theme 'We are so much than...', stated "We learned from other cultures and they really learned about our culture." During the same group interview, Liliana, a female student at CCT, registered her feelings that the project was a success saying, "It makes us more confident and comfortable talking in English." The idea of being more confident and motivated to use the target language was also expressed by American students, as well, as a marker of the project's success. José, a senior recursive dynamic bilingual at $\mathrm{SCRI}{ }^{2} \mathrm{BE}$, expressed his satisfaction with the project in the following journal entry:

"I thought that today's CMC [computer mediated communication] was very fun getting to see what others thought of Mexico and what they felt their stereotypes were. I also realized that I should start trying to read Spanish more than I have and I enjoy this as a chance to get to do it more often, plus writing in Spanish also feels good."

An inference that might be drawn from these comments is that purposeful CS could provide a safe and comfortable structure for trying to communicate in one's L2.

These quotes lend support to the potential of CS as a pedagogical intervention that promotes 'successful' communication in transnational telecollaboration projects. The 
voices shared above and their perceptions of $\mathrm{L} 2$ and intercultural learning, positive identity creation, and relationship building, offer harmony amidst the cacophony of stories about failed and missed communication traditionally reported on in the literature. These findings point to increased attention on pedagogically preparing students with strategies for organizing bilingual discourse, such as CS at phatic/referential switches, as an important component of mediating the development of symbolic competence in the classroom.

\section{Conclusion}

Above, I have related a positive account of intercultural communication in a high school Spanish-English telecollaboration project that stands in contrast to several seminal articles that focus somewhat on what educators might actually do to improve intercultural communication, but mostly on the dysfunctions that explain past 'failed' communicative interactions in telecollaboration projects (O'Dowd \& Ritter, 2013; Ware, 2005). There have been calls for "calculated pedagogical interventions" for successful communication via telecollaboration (Belz, 2002, p. 75; see also Lantolf \& Pavlenko, 2001), but in describing the use and potential positive impact of the FACE approach, this study represents one of the first to put forth such a calculated pedagogical intervention. Creese \& Blackledge (2010) state that "codeswitching is rarely institutionally endorsed or pedagogically underpinned" (p. 105). It is my hope that describing the FACE framework in this study can both strongly endorse CS in the classroom and provide a firm pedagogical underpinning for translanguaging practices.

Successfully communicating in next-generation education demands that educators consider how online and ubiquitous mobile interactions afford learners to construct anonymous identities. In a Web 2.0 environment, where users can contribute content and co-construct knowledge available on the internet, it is imperative that we take a critical look at how users negotiate their language use globally, what identities they develop both globally and locally (glocally) as a result of this interaction, and whether they have the symbolic competence needed to flow between multiple identities as they make moves within the power game being played out across online borders and contact zones. Can CS online perhaps lead to CS offline and to a hybridity of glocal identities?

This study is a call to action for educators to rethink language learning and practice in next-generation CALL. Code-switching in telecollaboration provides teachers and learners the opportunity to go beyond "static depictions of culture and monolithic target-language identities", to the analysis of and participation with "quotidian realities of multilingualism....and the multiplicity of meaning and identity" (Belz \& Thorne, 2006, p. $x$ ). Through interacting with others online "we find out who we are and who we are making ourselves to be" (Kramsch, 2000, p. 83). Are our students different people with their fingers on a computer keyboard or when their thumbs are stroking and jabbing at the screen of a phone? Belz (2005) states "If one adopts a social semiotic perspective on language....in which ideology (attitudes, beliefs, values) is thought to be reflected in 
linguistic structure, then a close examination of the linguistic details of interaction is essential in order to gain insight into the attitudes encoded in that structure" (p. 7). As the ubiquity of CALL in the classroom continues to entice educators to connect their students with greater ease with classrooms around the world and romances school districts to herald the globalized environments of their schools, I believe that CS is one such linguistic detail of interaction that deserves and should continue to receive much attention. 


\section{References}

Androutsopoulos, J. (2007). Bilingualism in the mass media and on the Internet. In Bilingualism: A social approach (pp. 207-230). Palgrave Macmillan UK.

Androutsopoulos, J. (2013). Code-switching in computer-mediated communication. Pragmatics of computer-mediated communication, 659-686.

Arthur, J., \& Martin, P. (2006). Accomplishing lessons in postcolonial classrooms: Comparative perspectives from Botswana and Brunei Darussalam. Comparative education, 42(02), 177-202.

Belz, J. A. (2002). Social dimensions of telecollaborative foreign language study. Language Learning \& Technology, 6 (1), 60-81. Retrieved from http://lt.msu.edu/ vol6num1/BELZ/default.html

Belz, J. A. (2005). Intercultural questioning, discovery and tension in Internet-mediated language learning partnerships. Language and Intercultural Communication, 5(1), 3-39.

Belz, J. A., \& Müller-Hartmann, A. (2002). Deutsch-Amerikanische Telekollaboration im Fremdsprachenunterricht-Lernende im Kreuzfeuer der institutionellen Zwänge. Die Unterrichtspraxis/Teaching German, 35 (1), 68-78.

Belz, J. A., \& Müller-Hartmann, A. (2003). Teachers negotiating German-American telecollaboration: Between a rock and an institutional hard place. Modern Language Journal, 87 (1), 71-89.

Belz, J. A. \& S. L. Thorne (2006). Introduction: Internet-mediated intercultural foreign language education and the intercultural speaker. In J. A. Belz \& S. Thorne (eds.), Internet-mediated intercultural foreign language education. Boston, MA: Thomson Heinle, iix-xxv.

Brown, P., \& Levinson, S. (1987). Politeness: Some universals in language. Cambridge: Cambridge University.

Creese, A., \& Blackledge, A. (2010). Translanguaging in the bilingual classroom: A pedagogy for learning and teaching?. The Modern Language Journal, 94(1), 103-115.

Eggins, S. (2004). Introduction to systemic functional linguistics. A\&C Black.

Fant, L., \& Grindsted, A. (1995). Conflict and consensus in Spanish vs. Scandinavian negotiation interaction. Hermes Journal of Linguistics, 15, 111-141. 
García, O., \& Sylvan, C. E. (2011). Pedagogies and practices in multilingual classrooms: Singularities in pluralities. The Modern Language Journal, 95(3), 385-400.

Goffman, E. (1955). On face-work: An analysis of ritual elements in social interaction. Psychiatry: Journal for the Study of Interpersonal Processes.

Grindsted, A. (1994). The impact of cultural styles on negotiation: a case study of Spaniards and Danes. Professional Communication, IEEE Transactions on, 37(1), 34-38.

Grindsted, A. (1995). Dyadic and polyadic sequencing patterns in Spanish and Danish negotiation interaction. The discourse of business negotiation, 8, 203.

Halliday, M.A.K. (1978). Language as social semiotic: The social interpretation of language and meaning. London: Edward Arnold/Baltimore, MD: University Park Press.

Jakobson, R. (1990). The speech event and the functions of language. On language, 69-79.

Kramsch, C. (2000). Authenticity and authorship in the computer-mediated acquisition of L2 literacy. Language Learning \& Technology, 4(2), 78-104.

Kramsch, C. (2006). From communicative competence to symbolic competence. The Modern Language Journal, 90(2), 249-252.

Kramsch, C. J. (2009). The multilingual subject: What foreign language learners say about their experience and why it matters. Oxford University Press.

Kramsch, C., \& Thorne, S. (2002). Foreign language learning as global communicative practice. Globalization and language teaching, 83-100.

Kramsch, C., \& Whiteside, A. (2008). Language ecology in multilingual settings. Towards a theory of symbolic competence. Applied linguistics, 29(4), 645-671.

Lantolf, J. P., \& Pavlenko, A. (2001). (S)econd (L)anguage (A)ctivity theory: Understanding second language learners as people. In M. Breen (Ed.), Learner contributions to language learning: New directions in research (pp. 141-158). New York: Longman.

Martin, J. R. (2000). Close reading: Functional linguistics as a tool for critical discourse analysis. Researching language in schools and communities: Functional linguistic perspectives. L. Unsworth. London, Cassell: 275-302.

Müller-Hartmann, A. (2000a). The role of tasks in promoting intercultural learning in electronic learning networks. Language Learning \& Technology, 4(2), 129-147. 
O'Dowd, R. (2003). Understanding 'the other side': Intercultural learning in a SpanishEnglish e-mail exchange. Language Learning \& Technology, 7 (2), 118-144. http://lt.msu.edu/vol7num2/odowd/default.html

O'Dowd, R. (2005). Negotiating sociocultural and institutional contexts: The case of Span- ish-American telecollaboration. Language and Intercultural Communication, 5(1), 40-56.

O'Dowd, R., \& Ritter, M. (2013). Understanding and working with'failed communication'in telecollaborative exchanges. CALICO journal, 23(3), 623-642.

Otheguy, R., García, O., \& Reid, W. (2015). Clarifying translanguaging and deconstructing named languages: A perspective from linguistics. Applied Linguistics Review, 6(3), 281-307.

Park, J. R. (2008). Linguistic politeness and face-work in computer-mediated communication, Part 1: A theoretical framework. Journal of the American Society for Information Science and Technology, 59(13), 2051-2059.

Placencia, M. E. (1998). Pragmatic variation: Ecuadorian Spanish vs. Peninsular Spanish. Spanish Applied Linguistics, 2(1), 71-106.

Placencia, M. E. (2005). Pragmatic variation in corner store interactions in Quito and Madrid. Hispania, 583-598.

Przymus, S.D. (2014). Negotiating language use in CALL's fourth phase: Introducing a Functional Approach to Code-switching Electronically (FACE). Arizona Working Papers in SLA \& Teaching, 21

Przymus, S.D. (2016). Challenging the monolingual paradigm in secondary duallanguage instruction: Reducing language-as-problem with the 2-1-L2 model. Bilingual Research Journal, 39(3-4), 279-295.

Przymus, S.D. (In press). Appropriate assessment y instrucción de los emergent bilinguals con disabilities. In Jimerson, J.B. \& Quebec Fuentes, S. (Eds.), Instructional Leadership in the Content Areas: Case Studies for Curriculum and Instruction. Book accepted for publication by a joint imprint of Routledge/ University Council for Educational Administration (UCEA), slated for 2019 release.

Thorne, S. L., \& Black, R. W. (2007). Language and literacy development in computermediated contexts and communities. Annual Review of Applied Linguistics, 27, 133-160.

Tsiplakou, S. (2010). Doing (bi) lingualism: Language alternation as performative construction of online identities. Pragmatics, 19(3). 
Vinall, K. (2010). The limits of communicative language teaching: Symbolic competence and the multiplicity of meaning. Unpublished paper.

Ware, P. (2005). Missed communication in online communication: Tensions in a German-American telecollaboration. Language Learning \& Technology, 9(2), 6489.

Ware, P. D., \& Kramsch, C. (2005). Toward an intercultural stance: Teaching German and English through telecollaboration. Modern Language Journal, 190-205.

Warschauer, M., \& Grimes, D. (2007). Audience, authorship, and artifact: The emergent semiotics of Web 2.0. Annual Review of Applied Linguistics, 27, 1-23. 